\title{
COVID-19 disposable face masks: a precursor for synthesis of valuable bioproducts
}

\author{
Oluwatosin Oginni ${ }^{1}$ (D)
}

Received: 23 May 2021 / Accepted: 26 June 2021 / Published online: 1 July 2021

(C) The Author(s), under exclusive licence to Springer-Verlag GmbH Germany, part of Springer Nature 2021

\begin{abstract}
Disposable face mask has become a mandatory personal protective equipment in order to prevent contracting COVID-19. With the significant surge in its usage, its adverse environmental impact is becoming a source of concern. Disposable face masks are made from thermoplastic polymers, and therefore they can be safely converted into valuable bioproducts. This paper discussed the possibility of converting waste/contaminated face masks into valuable bioproducts, which will essentially eliminate secondary transmission of the coronavirus and the concerns of environmental pollution.
\end{abstract}

Keywords COVID-19 $\cdot$ Disposable face masks $\cdot$ Bioproducts $\cdot$ Pyrolysis

According to the US Centers for Disease Control and Prevention Data Tracker, the total confirmed COVID-19 cases in the USA stands at 27.1 million with total death of 465,281 Prevention CFDCA (2021) while the total cases worldwide stand at 107,376,504 and a total death toll of 2,348,684, as of February 09, 2021 (Worldometer 2021). While the roll out of vaccines are underway to help combat this pandemic, both the World Health Organization (WHO) and the US Centers for Disease Control and Prevention have recommended preventive measures such as social distancing, hand sanitizers, frequent handwashing, and the use of face masks.

The recent surge in the total COVID-19 cases and spread of the coronavirus outbreaks in new parts of the USA has led to a significant increase in the use of face masks. For example, between June and August 2020, the result of a survey conducted by Pew Research Center showed that there was a 23\%, $27 \%, 28 \%$, and $33 \%$ increase in the use of face masks by US adults in the West North Central, West South Central, East South Central, and Mountain regions, respectively (Kramer 2020). This is an indication that more US adults regardless of their political affiliations and perspectives are now considering face masks to be an effective personal protective

Responsible Editor: Lotfi Aleya

Oluwatosin Oginni

frankjerry3729@gmail.com

1 School of Forest Resources, The University of Maine, 322 Nutting Hall, Orono, ME 04469, USA equipment. Public health and medical officials have described face mask to be a simple barrier which prevent respiratory droplets from reaching others, thereby substantially slowing down the transmission of the coronavirus Prevention CFDCA (2021).

With the significant increase in the use of face masks, there is a concern about the safe disposal of these waste materials (Nzediegwu and Chang 2020). Specifically, handling of waste disposable face masks will compound the current environmental problems constituted by the large volume of various plastics that are disposed in water bodies. This is because disposable face masks are made from polymers such as polypropylene, polyurethane, polyacrylonitrile, polystyrene, polycarbonate, polyethylene, or polyester (Fadare and Okoffo 2020; Potluri and Needham 2005) and they are not biodegradable. Fadare and Okoffo (Fadare and Okoffo 2020) stated that the high rate of single use of disposable face masks will emerge as a new source of microplastic fibers in the environment. Nzediewu and Chang (Nzediegwu and Chang 2020) stated that improper handling of waste COVID-19 preventive gears can increase the spread of COVID-19 in developing countries. The United Nations Environment Program (News 2020) estimates that about $75 \%$ of used face masks and other pandemic-related wastes will end up in landfills or waterbodies. If the disposal of these waste materials are not properly managed, it can ultimately result in public health risks such as secondary transmission from contaminated used face masks. This is supported by a study conducted by Kampf et al. (Kampf et al. 2020), investigating the persistence of 
coronavirus on inanimate surfaces and reported that the human coronavirus can remain infectious on inanimate surfaces at room temperature for up to 9 days and an increase in temperature above $30^{\circ} \mathrm{C}$ will result in shorter persistence duration of the coronavirus.

While the disposal and management of used face masks and other pandemic-related materials may present an environmental challenge, these waste resources can be converted to valuable bioproducts. Fadare and Okorro (Fadare and Okoffo 2020) conducted an FTIR analysis of disposable face masks and reported that the inner and outer layers of the disposable face masks presented a characteristic peak of polypropylene and high-density polyethylene, respectively. Polypropylene and high-density polyethylene are thermoplastic hydrocarbon polymers produced from propylene and ethylene monomers, respectively. Due to their hydrocarbon nature, they can be converted to valuable bioproducts such as syngas, bio-oil, and biochars. This implies that the vast quantity of used disposable face masks can serve as reliable feedstock for bioproducts synthesis.

In comparison to lignocellulosic feedstocks, polymeric materials such as disposable face masks have been shown to have impeccable characteristics such as low moisture content $(0.00-0.80 \%)$, low ash content $(0.00-1.40 \%)$, and high volatile content (86.83-99.63\%) (Jouhara et al. 2018). Bioproducts obtained from the thermochemical conversion of disposable face masks will therefore not have physicochemical characteristics inhibiting the direct utilization of lignocellulosic feedstock-derived bioproducts.

Pyrolysis is a thermochemical conversion technology which involves the thermal decomposition of a material at a temperature above $400{ }^{\circ} \mathrm{C}$ in the absence of oxygen to produce bio-oil, biochar, and non-condensable gas (Oginni and Singh 2019; Oginni et al. 2017). This conversion technology has been reported in various literatures to convert lignocellulosic and non-lignocellulosic feedstocks to bio-oil and biochar. For example, Ahmad et al. (Ahmad et al. 2014) investigated the pyrolysis of polypropylene (PP) and high-density polyethylene (HDPE) at temperature range of $250-400{ }^{\circ} \mathrm{C}$. Optimum bio-oil yields of $69.82 \%$ and $80.88 \%$ were obtained at pyrolysis temperature of $300{ }^{\circ} \mathrm{C}$ and $350{ }^{\circ} \mathrm{C}$ for PP and HDPE, respectively. Jung et al. (Jung et al. 2010) also investigated the pyrolysis of waste polypropylene and polyethylene in a fluidized bed reactor at a temperature range of 650-750 ${ }^{\circ} \mathrm{C}$ and reported a bio-oil yield of $43 \%$ and $53 \%$ for polypropylene and polyethylene, respectively.

The bio-oils obtained from pyrolysis of polypropylene and polyethylene have been reported to have a very high calorific value, which is almost equivalent to the calorific value of the conventional liquid fuel. For example, Lopez et al. (López et al. 2011) reported calorific values of $40.8-43.5 \mathrm{MJ} / \mathrm{kg}$ for bio-oils produced from pyrolysis of plastic mixtures at temperature range of $460-600{ }^{\circ} \mathrm{C}$. Paradela et al. (Paradela et al.
2009) also reported a calorific value of $44.7 \mathrm{MJ} / \mathrm{kg}$ for bio-oil obtained from pyrolysis of plastic wastes at temperature of $450{ }^{\circ} \mathrm{C}$

Biochar is a solid porous carbonaceous product obtained from pyrolysis (Oginni and Singh 2020). Due to its tunable physicochemical characteristics, it has been explored extensively for soil amendment, carbon sequestration, water treatment, residential heating, catalyst, and energy storage. The use of disposable face masks for producing biochar is significantly dependent on the carbonization temperature. Due to the high temperature required to thermally decompose thermoplastics and the low fixed carbon content of these materials, biochar yield is generally very low. Papuga et al. (Papuga et al. 2015) reported a decrease in biochar yield from 25.46 to $1.23 \%$ during pyrolysis of waste plastics mixture (45\% polypropylene, $35 \%$ low-density polyethylene, and $25 \%$ high-density polyethylene) as pyrolysis temperature increased from 450 to $525{ }^{\circ} \mathrm{C}$. Lopez et al. (López et al. 2011) reported a very low biochar yield of $0.8-1.1 \%$ during pyrolysis of plastic mixture (40 wt\% polyethylene, $35 \mathrm{wt} \%$ polypropylene, $18 \mathrm{wt} \%$ polystyrene, $4 \mathrm{wt} \% \mathrm{PET}$, and $3 \% \mathrm{PVC}$ ) at temperature range of $460-600{ }^{\circ} \mathrm{C}$. This implies that biochar production from waste face masks may not be as high as bio-oil production.

Since the persistent duration of coronavirus decreases as temperature increases, the use of waste/contaminated disposable face masks as a precursor for bio-oil and biochar production will not present any danger of secondary transmission as the virus will not be able to survive the temperature at which this thermochemical conversion process is taking place. However, in the consideration of pyrolysis technology to safely handle waste/contaminated disposable face masks, it will be recommended that these masks are collected separately just as plastic bottles and other recyclable waste materials are collected. This will eliminate the need for sorting the masks from other waste materials.

The World Health Organization estimated a monthly global consumption and waste of 129 billion face masks and the weight of a face mask is $3.5 \mathrm{~g}$. Therefore, a total of 451.5 billion grams of waste face masks is generated monthly worldwide. Based on the bio-oil yield range (43-80\%) that has been reported in literatures during pyrolysis of plastics, it can be estimated that a total of 194.2-361.2 billion grams of bio-oil can be generated monthly from these waste face masks worldwide. This is an indication that while the disposal of used face masks seemed to present itself as an environmental pollutant, it can be safely converted into useful valuable bioproducts.

\section{Conclusion}

Disposable face masks are personal protective equipment recommended to prevent COVID-19 transmission. In this study, 
pyrolysis has been identified as a tested conversion technology which can be utilized to convert contaminated face masks into high valued bioproducts such as bio-oil and biochar while also eliminating any possibility of COVID-19 transmission as the virus cannot survive the operational temperature of this conversion technology.

Availability of data and materials Not applicable.

Author Contribution Conceptualization, investigation, resources, and writing were solely by the author.

\section{Declarations}

Ethics approval and consent to participate Not applicable.

Consent for publication Not applicable.

Competing interest The author declares no competing interests.

\section{References}

Ahmad I, Khan M, Khan H, Ishaq M, Tariq R, Gul K, Ahmad W (2014) Pyrolysis study of polypropylene and polyethylene into premium oil products. Int J Green Energy 12:140303064405005

Fadare OO, Okoffo ED (2020) Covid-19 face masks: a potential source of microplastic fibers in the environment. Sci Total Environ 737: 140279

Jouhara H, Ahmad D, van den Boogaert I, Katsou E, Simons S, Spencer N (2018) Pyrolysis of domestic based feedstock at temperatures up to $300{ }^{\circ} \mathrm{C}$. Thermal Sci Eng Progress 5:117-143

Jung S-H, Cho M-H, Kang B-S, Kim J-S (2010) Pyrolysis of a fraction of waste polypropylene and polyethylene for the recovery of BTX aromatics using a fluidized bed reactor. Fuel Process Technol 91: $277-284$

Kampf G, Todt D, Pfaender S, Steinmann E (2020) Persistence of coronaviruses on inanimate surfaces and their inactivation with biocidal agents. J Hosp Infect 104:246-251

Kramer S (2020) More Americans say they are regularly wearing masks in stores and other businesses. Pew Research Center

López A, de Marco I, Caballero BM, Laresgoiti MF, Adrados A (2011) Influence of time and temperature on pyrolysis of plastic wastes in a semi-batch reactor. Chem Eng J 173:62-71

News U (2020) Five things you should know about disposable masks and plastic pollution, Climate Change

Nzediegwu C, Chang SX (2020) Improper solid waste management increases potential for COVID-19 spread in developing countries. Resour Conserv Recycl 161:104947

Oginni O, Singh K (2019) Pyrolysis characteristics of Arundo donax harvested from a reclaimed mine land. Ind Crop Prod 133:44-53

Oginni O, Singh K (2020) Influence of high carbonization temperatures on microstructural and physicochemical characteristics of herbaceous biomass derived biochars. J Environ Chem Eng:104169

Oginni O, Singh K, Zondlo JW (2017) Pyrolysis of dedicated bioenergy crops grown on reclaimed mine land in West Virginia. J Anal Appl Pyrolysis 123:319-329

Papuga S, Gvero P, Vukić L (2015) Temperature and time influence on the waste plastics pyrolysis in the fixed bed reactor. Therm Sci 20: 154

Paradela F, Pinto F, Gulyurtlu I, Cabrita I, Lapa N (2009) Study of the copyrolysis of biomass and plastic wastes. Clean Techn Environ Policy 11:115-122

Potluri P, Needham P (2005) Technical textiles for protection. In: Scott RA (Editor), Textiles for protection. Woodhead Publishing 151-175

Prevention CFDCA (2021) COVID data tracker: COVID-19 cases and deaths in US

Worldometer (2021) COVID19 coronavirus pandemic

Publisher's note Springer Nature remains neutral with regard to jurisdictional claims in published maps and institutional affiliations. 